\title{
Invited commentary: Community treatment orders
}

\author{
Tom Burns
}

Moncrieff \& Smyth (1999, this issue) are certainly right that community treatment orders (CTOs) are high on the agenda and that psychiatrists need to think long and hard about them - about the political and ethical implications, not just their practical and therapeutic applications. Their concerns are important and reflect a wide constituency - identical views were expressed and considered during the consultation that preceded the College's document proposing a Community Supervision Order in 1993 (Royal College of Psychiatrists, 1993). Moncrieff \& Smyth make no mention of that document, nor the limited, but recent, survey of psychiatrists' opinions that accompanied it (Burns et al, 1993). Do all College documents achieve obscurity quite so quickly?

They are right that there is 'no quick fix' in humane care of the severely mentally ill, equally so about the need to be sceptical of external pressure and that the ostensibly 'technical' issue of a CTO has wider implications. If it is to work it needs to be broadly acceptable to all involved. A government fiat will not succeed. Their argument, however, contains some omissions and distortions which need to be addressed for the dialogue to progress.

Moncrieff \& Smyth use the classical debating technique of posing a different question to that under consideration, demolishing it and substituting a different one that suits their proposal. Concluding that CTOs are "the wrong solution to the wrong question" they imply that the question was "how can psychiatry control antisocial behaviour?" This was not the question - if it were few psychiatrists would support a CTO. The question was "is there a group of patients who are poorly served by the present legislation, who are currently repeatedly subject to compulsory admission and whose welfare would be better served by a CTO?"

College members were clear that a CTO would contribute little to the problems of violence or the homeless mentally ill. To work it has to be part of a broader treatment package and relationship between professional and patient - it cannot substitute for either. There is no pretence that this relationship is equal or entirely voluntary. but it has to be negotiated. The patient has to understand the implications of the order and agree with it. The results of a simple, local survey (Burns et al, 1993) found the numbers of patients estimated to benefit from the approach were small (a handful per team) and well known. Most support during preliminary consultations came from younger psychiatrists whose training had exposed them to community work, whereas older psychiatrists who had predominantly trained and worked in mental hospitals could see no practical use for them.

There are a number of specific points in Moncrieff \& Smyth's case that call for comment. Their remarks about civil liberties and the need for tolerance are hardly specific to CTOs, but to compulsory treatment generally. Where would they set the threshold? Is there a role for compulsion in being ". . . prepared to help manage the consequences?" I'm also at a loss to understand how a CTO would increase stigma beyond that from repeated compulsory admissions as a prelude to needed treatment. The role of civil liberties in the deinstitutionalisation movement does not accord with my memory of that time - I can hardly remember the term being used. Rather, we were concerned to improve what today would probably be called the "quality of life' of patients whom we saw as missing out. It misrepresents the process to see it as removing constraints (very few long-term patients were detained). It was an active process (driven by clinicians) to encourage and rehabilitate demoralised and demotivated individuals.

Moncrieff \& Smyth list a series of practical objections to CTOs by rehearsing the limitations of our pharmacological treatments. Again a reading of the College's document would have gone a long way to answering these worries. The CTO proposed was to be restricted to patients with a demonstrated good response to medication under previous conditions of compulsion. There is no earthly purpose served by compelling someone to take medicines that do not work for them, nor would anyone suggest it. Similarly does anyone yet know whether long-term maintenance treatment on a CTO is more or less harmful than intermittent higher doses for 
repeated relapses? Psychiatrists have to weigh up (and discuss) the pros and cons of any treatment with each individual, whether voluntary or compulsory. It's what we are paid for.

The discussion of violence and dangerous behaviour is essentially a red herring. Nobody within the profession has suggested that the CTO is a solution to this, or that a failure to be so invalidates the proposal. Moncrieff \& Smyth are, however, right to remind us that others may harbour such a misunderstanding.

The most surprising part of Moncrieff \& Smyth's case is the consideration of the practical consequences of a CTO. Its proposed capacity to alienate patients is couched in theoretical terms. It's as if we do not have considerable experience of the use of such compulsion already. Have none of their group worked in Scotland, or in England with psychiatrists like me who use Section 17 leave (and now supervised discharge) extensively? Much of what is proposed already exists, albeit for too short a period and still requires a compulsory admission to initiate it. I've had lots of experience of negotiating compulsion in this way with patients. It never works unless there is at least some working relationship and ability to find a compromise. Sometimes it works and sometimes it doesn't, but I've never experienced it alienating patients. It isn't something you impose on a patient but something you negotiate. If it becomes clear that there is not going to be agreement there is neither purpose nor (in the College's proposal) the legal possibility to impose it. With many patients we then simply have to accept the cycle of relapse and admission.

Therapeutic relationships are not twodimensional. Like most human relationships they have many layers and contain paradoxes and ambiguities. The unequal power balance in the doctor-patient (or nurse-service user) relationship is probably better understood by our patients than by us, even as we work to reduce it and encourage partnership. Asymmetry in a relationship, however, does not proscribe mutual respect any more than authority can be sensibly exercised in the absence of consensus. Within this framework a CTO is potentially a vital element in helping to keep a small group of people well, thereby reducing the marginalisation and social invalidation that can come from repeated, disruptive hospital admissions. Moncrieff \& Smyth rightly highlight that attempting to use it as an alternative, rather than an adjunct, to a therapeutic relationship, or allowing its purpose to be hijacked for political purposes, would soon backfire. They might be reassured in reading the College's document to find that most of their concerns have been carefully considered before coming to a different conclusion - namely that a CTO is a humane and necessary part of modern mental health care.

\section{References}

BURNS. T., GODDARD, K. \& BALE, R. (1993) Mental health professionals favour community supervision orders. British Medical Joumal, s07. 803.

MONCRIEFF, J. \& SMYTH, M. (1999) Community treatment orders-a bridge too far? Psychiatric Bulletin. 23. 644-646.

Royal College of PSYchiatrists (1993) Community Supervision Onders. Councll Report CR18. London: Royal College of Psychiatrists.

Tom Burns, Head of Community Psychiatry. Department of General Psychiatry. St George's Medical School, University of London, Jenner Wing. Cranmer Terrace, London SW17 ORE 